\title{
The importance of a valid assessment of salt intake in individuals and populations. A scientific statement of the British and Irish Hypertension Society
}

\author{
Francesco P. Cappuccio $\mathbb{1}^{1,2} \cdot$ Peter S. Sever ${ }^{3} \cdot$ on behalf of the British and Irish Hypertension Society
}

Received: 28 March 2019 / Accepted: 4 April 2019 / Published online: 26 April 2019

(c) The Author(s) 2019. This article is published with open access

\section{Introduction}

High salt (salt is sodium chloride $-2.5 \mathrm{~g}$ of salt contain $1 \mathrm{~g}$ of sodium) intake is a major determinant of blood pressure (BP) in individuals and populations [1]. A reduction of salt intake leads to a reduction in BP and is associated with a reduction in the incidence of cardiovascular disease (CVD) [1-3]. However, in the past few years, some epidemiological studies suggested the presence of a J-shaped association between salt (sodium) consumption and CVD [4-9]. These results sparked both scientific and media interest and opened a debate on the wisdom of pursuing populationwide salt reduction policies to reduce CVD, as currently recommended by most national and international health organizations, including the World Health Organization (WHO) [10]. Systematic appraisal of these studies identified a variety of pitfalls, suggesting that their results were based on flawed methodologies [11, 12]. The present scientific statement aims to briefly discuss only one such flaw, the use of biased methods of assessing salt consumption, and the consequences of using such biased estimates of exposure (salt intake) when assessing both individual salt intake (for associations with CVD) and population salt consumption (to evaluate population salt reduction programmes).

British and Irish Hypertension Society

bihs@in-conference.org.uk

1 University of Warwick, WHO Collaborating Centre for Nutrition, Warwick Medical School, Coventry, UK

2 University Hospitals Coventry \& Warwickshire NHS Trust, Coventry, UK

3 Imperial College London, National Heart \& Lung Institute, London, UK

\section{Assessment of salt intake}

The assessment of salt intake is fraught with difficulties. Nutritional tools based on either questionnaires or food diaries are inadequate to characterise salt consumption of individuals and populations when compared with biomarkers, and are not recommended as research tools for this purpose $[13,14]$. The $24 \mathrm{~h}$ urinary excretion of sodium is considered the reference method to assess salt consumption, since $\sim 93 \%$ of the sodium ingested, mostly as salt (salt is sodium chloride $-2.5 \mathrm{~g}$ of salt contain $1 \mathrm{~g}$ of sodium), is eliminated by the kidney in the next $24 \mathrm{~h}$ [15]. If we ate the same amount of salt every day, a single $24 \mathrm{~h}$ urine collection would indicate with a high degree of precision how much salt we eat. However, due to the high variability of salt consumption in an individual between days and some infradian variability in urinary sodium excretion, independent of intake, many more collections on different days would be required to characterize the habitual individual's salt consumption [16]. Therefore multiple assessments are needed, in prospective studies, to obtain a reliable estimate of the degree of association between habitual salt consumption and future risk of CVD [3, 17-19]. To overcome the high methodological burden of collecting complete $24 \mathrm{~h}$ urine samples in large population-based studies in some settings, then, alternative easier methods have been proposed. Amongst those alternatives the use of 'spot' urine collections and the application of different formulae (e.g. Kawasaki, Tanaka, INTERSALT) to derive $24 \mathrm{~h}$ urinary sodium excretion have become of popular use [4-9]. The commonest is the Kawasaki [20]. This formula relies on urinary creatinine concentration from a spot collection and $24 \mathrm{~h}$ urinary creatinine excretion predicted from age, sex, height, and weight. It is, however, an inappropriate method for estimating salt intake in individuals, due to its unreliability and systematic bias [18]. These extrapolations consistently overestimate at lower levels of salt intake and 

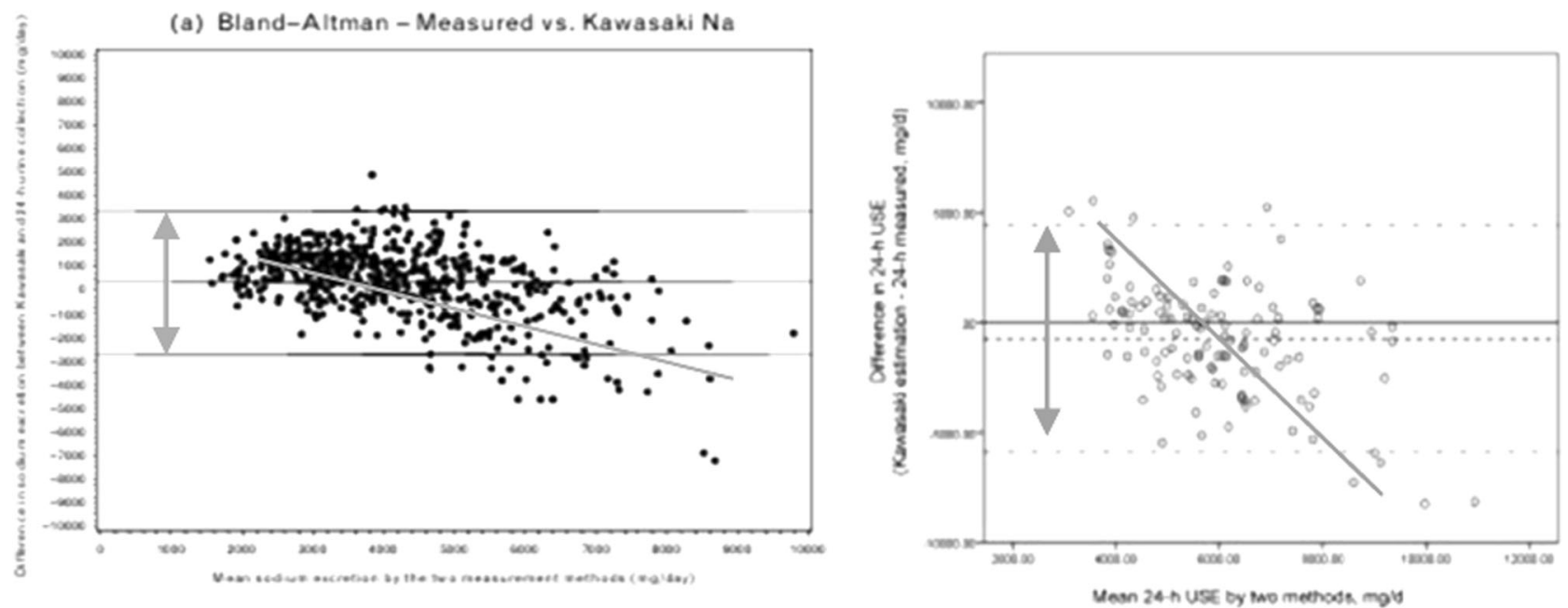

Fig. 1 Validation and comparison of the Kawasaki formula to estimate $24 \mathrm{~h}$ urinary sodium excretion from a single morning spot urine sample in the PURE Study. On the left it is the validation in 1083 participants from 11 countries $^{\dagger}$ and on the right it is the validation in 120 participants from the Shanxi Province of China ${ }^{\#} .{ }^{\dagger} 1083$ consecutive individuals attending follow-up clinics over a period of 2-6 months; 87

underestimate at higher levels, introducing a systematic bias, detected in all validation studies performed to date, including the PURE Study [6-9, 12] (Fig. 1).

\section{Consequences of estimating 'individual' sodium excretion in associations studies between salt intake and CVD}

An accurate and unbiased measurement of 'individual' dietary sodium consumption is paramount in aetiological epidemiology. In prospective studies, where multiple complete $24 \mathrm{~h}$ urinary sodium collections have been used to measure exposure to salt consumption, consistent and graded relationships have been described between sodium excretion and health outcomes (CVD and all-cause mortality) in general populations, as well as in patients groups [3, 17-19]. On the contrary, when studies have used the Kawasaki formula, a J-shaped relationship has been obtained [4-9]. Finally, when a head-to-head comparison was carried out between measures of salt consumption obtained from repeated $24 \mathrm{~h}$ urine collections compared to a spot urine, in the prospective assessment of salt and mortality, there was a graded relationship when salt consumption was assessed with multiple $24 \mathrm{~h}$ collections (with no evidence of increased risk at lower levels up to $3 \mathrm{~g}$ of salt per day) whereas an 'erroneous' J-shaped curve was generated when using the Kawasaki formula from spot urines [21] (Fig. 2a). Therefore 'spot' urine collections with the use of the Kawasaki formula are an inappropriate method for studying associations in individuals in prospective

(a)
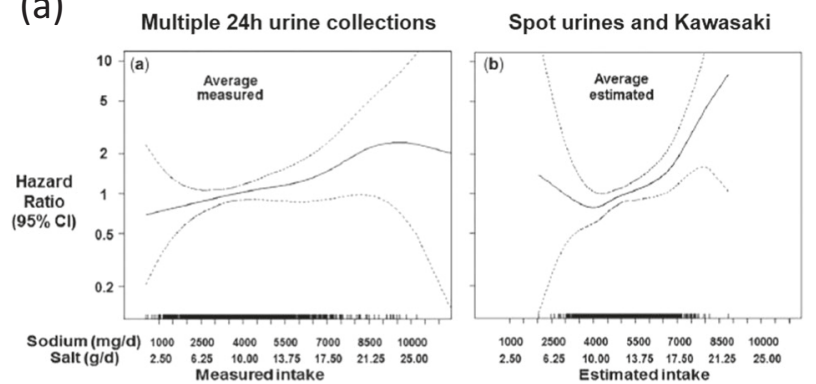

(b)

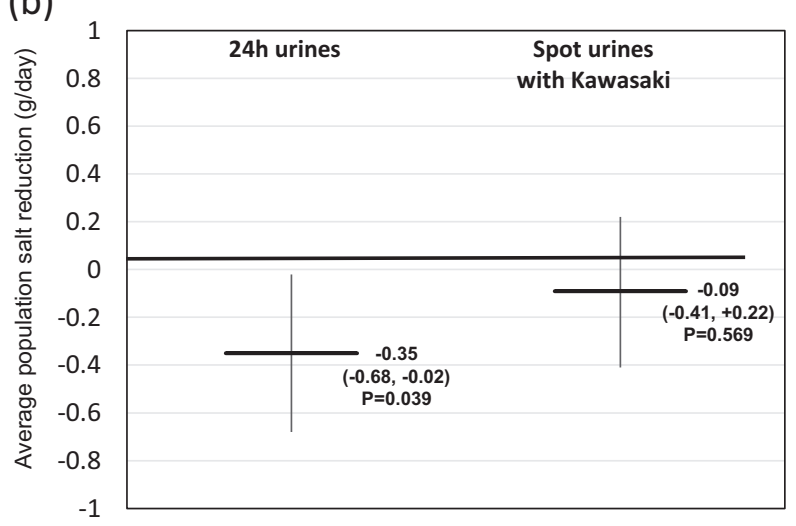

Fig. 2 a Errors in estimating usual sodium intake by the Kawasaki formula alter its relationship with mortality. Head-to-head comparison with $24 \mathrm{~h}$ urinary sodium excretion. Re-drawn from He FJ, et al. Int J Epidemiol. 2018;47:1784-95. b Spot urine collections with Kawasaki equation is inadequate to monitor changes in population salt reduction programmes. Head-to-head comparison with $24 \mathrm{~h}$ urinary sodium excretion. Drawn from Huang L, et al. Int J Epidemiol 2018; 47:1811-20 
studies, and should not be used in the context of prospective assessment of salt consumption as a predictor of health outcomes.

\section{Consequences of estimating 'population' average salt consumption in the evaluation of salt reduction programmes}

An accurate and unbiased measurement of 'average' dietary sodium consumption in population groups is paramount in public health and policy. The knowledge of a reliable estimate of population intake will help public health professionals in several ways. First, it will establish the size of the problem. (How much salt does my population eat?) Second, it will provide the gap from set targets. (How much do I have to reduce the average salt consumption to achieve WHO targets of $5 \mathrm{~g}$ per day?) Third, it will help evaluate the intervention in populations by determining changes in average intake over time. Fourth, it will inform health economic evaluations of health impact and motivate continuous political commitment. So, the choice of the right method for measuring salt consumption is equally important in this setting. In a recent study in South Africa, the validity of different formulas-including Kawasaki-applied to spot urine estimates of sodium were tested against $24 \mathrm{~h}$ urinary sodium measurements. The study showed that these formulas all fall short of an ideal scenario when assessing the presence and size of the bias [22]. In the case of the Kawasaki formula the size of the bias was equivalent to $5.6 \mathrm{~g}$ of salt [22]. The important implication of these results for policy is that all these formulas introduce a bias with large inaccuracy both in the baseline estimation and, more importantly, they do not enable them to detect smaller changes in population salt consumption over time ensuing from salt reduction programmes. For instance, if spot urines with Kawasaki estimates had been applied to the evaluation of the 8-year UK national salt reduction programme, a detection of $1.4 \mathrm{~g}$ per day reduction achieved over that period would not have been easy to detect given the presence of a bias three times as large. Therefore, the effectiveness of the population intervention would have been missed, with crucial implications for further investments and commitments towards that public health [23]. The real possibility of this scenario has been reported in the recent head-to-head comparison of an evaluation of the effectiveness of a 6-to-24 months salt-substitution programme in China within the framework of a well-controlled randomised clinical trial [24]. Over the time of intervention there was a statistically significant reduction in average sodium consumption of $0.35 \mathrm{~g}$ per day $(p=0.039)$ when assessed by $24 \mathrm{~h}$ urinary sodium excretion. However, when spot urines with Kawasaki equation were used, the change was detected as $-0.09 \mathrm{~g}$ per day $(p=0.569)$, a quarter of the real effect (Fig. 2b). Therefore 'spot' urine collections with the use of the Kawasaki formula are an inappropriate method for studying population chages and should not be used in the context of a public health evaluation of the effectiveness of salt reduction programmes.

\section{Conclusions}

The evidence supporting global actions for a moderate reduction in salt consumption to prevent CVD is strong and new controversial studies, based on flawed methodology, are inappropriate to address the complex associations between salt intake and CVD outcomes and the evaluation of population salt reduction programmes. They should not overturn the ongoing concerted public health action to reduce salt intake globally.

\section{Compliance with ethical standards}

Conflict of interest FPC is a technical advisor to the World Health Organization, President and Trustee of the British and Irish Hypertension Society. PSS declares that he has no conflict of interest.

Publisher's note: Springer Nature remains neutral with regard to jurisdictional claims in published maps and institutional affiliations.

Open Access This article is licensed under a Creative Commons Attribution 4.0 International License, which permits use, sharing, adaptation, distribution and reproduction in any medium or format, as long as you give appropriate credit to the original author(s) and the source, provide a link to the Creative Commons license, and indicate if changes were made. The images or other third party material in this article are included in the article's Creative Commons license, unless indicated otherwise in a credit line to the material. If material is not included in the article's Creative Commons license and your intended use is not permitted by statutory regulation or exceeds the permitted use, you will need to obtain permission directly from the copyright holder. To view a copy of this license, visit http://creativecommons.org/licenses/by/4.0/.

\section{References}

1. Aburto NJ, Ziolkovska A, Hooper L, Elliott P, Cappuccio FP, Meerpohl JJ. Effect of lower sodium intake on health: systematic review and meta-analyses. Br Med J. 2013;346:f1326.

2. He FJ, MacGregor GA. Salt reduction lowers cardiovascular risk: meta-analysis of outcome trials. Lancet. 2011;378:380-2.

3. Cook NR, Appel LJ, Whelton PK. Lower levels of sodium intake and reduced cardiovascular risk. Circulation. 2014;129: 981-9.

4. O'Donnell M, Mente A, Rangarajan S, et al. Urinary sodium and potassium excretion, mortality, and cardiovascular events. N Engl J Med. 2014;371:612-23.

5. O'Donnell MJ, Yusuf S, Mente A, Gao P, Mann JF, Teo K, et al. Urinary sodium and potassium excretion and risk of cardiovascular events. JAMA. 2011;306:2229-38. 
6. Mente A, O’Donnell MJ, Rangarajan S, Matthew J, McQueen MJ, Poirier $\mathrm{P}$, et al. Association of urinary sodium and potassium excretion with blood pressure. N Engl J Med. 2014;371:601-11.

7. Mente A, O’Donnell M, Rangarajan S, Dagenais G, Lear S, McQueen M, et al. Associations of urinary sodium excretion with cardiovascular events in individuals with and without hypertension: a pooled analysis of data from four studies. Lancet. 2016;388:465-75.

8. Mente A, O'Donnell M, Rangarajan S, McQueen M, Dagenais G, Wielgoz A, et al. Urinary sodium excretion, blood pressure, cardiovascular disease, and mortality: a community-level prospective epidemiological cohort study. Lancet. 2018;392:496-506.

9. O'Donnell M, Mente A, Rangarajan S, McQueen MJ, O'Leary N, Yin L, et al. Joint association of urinary sodium and potassium excretion with cardiovascular events and mortality: prospective cohort study. Br Med J. 2019;364:I772.

10. World Health Organization. Guideline: sodium intake for adults and children. Geneva: World Health Organization; 2012. p. 1-46.

11. Cobb LK, Anderson CA, Elliott P, Hu FB, Liu K, Neaton JD, et al. Methodological issues in cohort studies that relate sodium intake to cardiovascular disease outcomes: a science advisory from the American Heart Association. Circulation. 2014; 129:1173-86.

12. Cappuccio FP, Beer M, Strazzullo P. on behalf of the European Salt Action Network. Population dietary salt reduction and the risk of cardiovascular disease. A scientific statement from the European Salt Action Network. Nutr Metab Cardiovasc Dis. 2019;29: 107-14.

13. McLean RM, Farmer VL, Nettleton A, Cameron CM, Cook NR, Campbell NRC. Assessment of dietary sodium intake using a food frequency questionnaire and 24-hour urinary sodium excretion: a systematic literature review. J Clin Hypertens. 2017; 19:1214-30.

14. McLean RM, Farmer VL, Nettleton A, Cameron CM, Cook NR, Woodward M, et al. Twenty-four-hour diet recall and diet records compared with 24-hour urinary excretion to predict an individual's sodium consumption: a systematic review. J Clin Hypertens. 2018;20:1360-76.
15. Lucko AM, Doktorchick C, Woodward M, Cogswell M, Neal B, Rabi D, et al. Percentage of ingested sodium excreted in 24-hour urine collections: a systematic review and meta-analysis. J Clin Hypertens. 2018;20:1220-9.

16. Lerchl K, Rakova N, Dahlmann A, Rauh M, Goller U, Basner M, et al. Agreement between 24-hour salt ingestion and sodium excretion in a controlled environment. Hypertension. 2015; 66:850-7.

17. Mills KT, Chen J, Yang W, Appel LJ, Kusek JW, Alper A, et al. Sodium excretion and the risk of cardiovascular disease in patients with chronic kidney disease. JAMA. 2016;315:2200-10.

18. Cook NR, Appel LJ, Whelton PK. Sodium intake and all-cause mortality over 20 years in the trials of hypertension prevention. J Am Coll Cardiol. 2016;68:1609-17.

19. Olde Engberink RHG, van den Hoek TC, van Noordenne ND, van den Born BH, Peters-Sengers H, Vogt L. Use of a single baseline versus multiyear 24-hour urine collection for estimation of longterm sodium intake and associated cardiovascular and renal risk. Circulation. 2017;136:917-26.

20. Kawasaki T, Itoh K, Uezono K, Sasaki H. A simple method for estimating $24 \mathrm{~h}$ urinary sodium and potassium excretion from second morning voiding urine specimen in adults. Clin Exp Pharm Physiol. 1993;20:7-14.

21. He FJ, Campbell NRC, Ma Y, MacGregor GA, Cogswell ME, Cook NR. Errors in estimating usual sodium intake by the Kawasaki formula alter its relationship with mortality: implications for public health. Int J Epidemiol. 2018;47:1784-95.

22. Swanepoel B, Schutte AE, Cockeran M, Steyn K, WentzelViljoen E. Monitoring the South African population's salt intake: spot urine v. 24 h urine. Public Health Nutr. 2018;21:480-8.

23. Cappuccio FP, D'Elia L. Evaluating population salt reduction programmes worldwide: the risk of cutting corners! Public Health Nutr. 2018;21:2161-3.

24. Huang L, Woodward M, Stepien S, Tian M, Yin X, Hao Z, et al. Spot urine samples compared with 24-h urine samples for estimating changes in urinary sodium and potassium excretion in the China Salt Substitute and Stroke Study. Int J Epidemiol. 2018;47: 1811-20. 